\title{
O que é ensino em mídias móveis? Aprendendo com a Universidade de Aveiro
}

\author{
Marcelo Anunciato* \\ Marcus Bastos**
}

\section{Resumo}

Esse artigo procura apresentar o conceito de ensino em mídias móveis, discutindo benefícios e limitações desta forma de aprendizagem. Entre os temas discutidos, estão a ubiquidade e a gamificação, que são aspectos da aprendizagem em dispositivos móveis, sendo a ubiquidade algo que a diferencia. Numa época em que as redes sociais são pervasivas, tornou-se um desafio prender a atenção dos usuários, ainda mais em se tratando de uma atividade que requer maior tempo e concentração. $\mathrm{O}$ texto analisa em maior profundidade um exemplo na Universidade de Aveiro, em Portugal, em que o Parque Infante Dom Pedro serve como cenário para um ambiente de aprendizagem gamificado.

Palavras-chave: mobilidade; aprendizado; celulares; conhecimento; educação

\section{What is mobile media education? Learning with the University of Aveiro}

\section{Abstract}

This article seeks to present the concept of Mobile Learning, discussing the benefits and limitations of this form of learning. Among the topics discussed are ubiquity and gamification, which are aspects of mobile learning, ubiquity being something that differentiates it. At a time when social networks are pervasive, it has become a challenge to hold the users' attention, even more so when it comes to an activity that requires more

* É Mestre em Tecnologias da Inteligência e Design Digital pela PUC-SP.

** É Doutor em Comunicação e Semiótica pela PUC-SP e professor do Programa de Pós-Graduação em Tecnologias da Inteligência e Design Digital da PUC-SP. marcusbastossp@icloud.com 
time and concentration. The text analyzes in greater depth an example at the University of Aveiro in Portugal, where Parque Infante Dom Pedro serves as the setting for a gamified learning environment.

Keywords: mobile; learning; smartphones; knowledge; education

\section{¿Qué es la educación en medios móviles? Aprendiendo con la Universidad de Aveiro}

\section{Resumen}

Este artículo busca presentar el concepto de enseñanza en medios móviles, discutiendo los beneficios y limitaciones de esta forma de aprendizaje. Entre los temas tratados se encuentran la ubicuidad y la gamificación, que son aspectos del aprendizaje en dispositivos móviles, siendo la ubicuidad algo que lo diferencia. En un momento en que las redes sociales son omnipresentes, se convirtió en un desafío mantener la atención de los usuarios, especialmente cuando se trata de una actividad que requiere más tiempo y concentración. El texto analiza con mayor profundidad un ejemplo en la Universidad de Aveiro, en Portugal, donde el Parque Infante Dom Pedro sirve como escenario para un entorno de aprendizaje ludificado.

Palabras clave: movilidad; aprendizaje; celulares; conocimiento; educación

\section{Introdução}

Ensinar é uma das atividades mais antigas da cultura humana. Com o surgimento das tecnologias digitais, os processos de ensino e aprendizagem passam por uma transformação como não acontecia deste o surgimento das primeiras universidades, no século 11. Nos últimos anos, além de significativas, estas mudanças vêm acontecendo em ritmo mais rápido, impulsionadas pelas inovações tecnológicas que surgem em ritmo cada vez mais vertiginoso. Assim, antes mesmo que os processos de ensino à distância tenham se consolidado, já surgem novas possibilidades com o surgimento de aparelhos portáteis como os tablets e celulares. Eles permitem o chamado ensino em mídias móveis. Mas afinal, do que se trata esta nova forma de educação?

Ensino em mídias móveis é a aprendizagem que ocorre através de um aparelho digital que o aprendiz pode carregar consigo e acessar em qualquer lugar que estiver. Parece prático, mas não é fá- 
cil ler um livro de filosofia chacoalhando entre um ponto de ônibus e outro. Como enfrentar o desafio de ensinar neste formato dispersivo, em que além da competição por atenção típica dos aparelhos digitais, há também a competição do próprio entorno? Aprender com tablets, leitores digitais e celulares com acesso à Internet e condições razoáveis para acesso a conteúdo multimídia é um desafio bem maior que o tamanho das telas diminutas diante do estudante. O desafio é maior ainda quando se nota que os especialistas não chegaram sequer a um nome consensual para os processos de ensino móvel. Conforme Garcia (2017, p. 92):

O mobile-learning (m-learning) enfatiza a aprendizagem em contexto de mobilidade, contrapondo-se a acessos fechados e presentes em bases fixas de desktop conectadas à internet. Assim, o m-learning abrange um tipo de aprendizagem que ocorre, a princípio, quando o aprendiz não se fixa em um lugar e, portanto, prescinde de uma localização predeterminada.

À medida que os dispositivos de comunicação foram tornando-se cada vez mais portáteis e, ao mesmo tempo, foram se tornando mais sofisticados em termos de recursos disponíveis, iniciou-se a chamada cultura nomádica, conforme definido em artigo de Patrick Lichty escrito quando quase ninguém tinha celulares ${ }^{1}$. Ao longo de seu desenvolvimento, estes pequenos aparelhos promoveram grandes mudanças, mudando a forma das pessoas se comunicarem, interagirem, produzirem, compartilharem, colaborarem e acessarem conteúdos. A cultura monádica torna mais intenso o processo de transformação das pessoas em cidadãos digitais que vem acontecendo desde os anos 1980, quando inicia a democratização dos computadores pessoais.

A Pesquisa Nacional por Amostra de Domicílios Contínua (PNAD Contínua), de 2018, constatou que nos domicílios com Internet, o telefone celular era utilizado como principal meio de aces-

Lichty, Patrick. Pensando a cultura nomádica: artes móveis e sociedade, in: Bastos, Marcus et alii. Mediações, Tecnologia, Espaço Público: panorama crítico da arte em mídias móveis. São Paulo: Conrad, 2010. 
so em $99,4 \%$ das residências rurais e $99,2 \%$ das residências urbanas. Em 45,5\% destes domicílios, o telefone celular foi o único meio de acesso à Internet. Apesar de impressionantes, estes números não mudam muito faz anos. Já faz tempo que em muitos países há praticamente um celular para cada habitante e é muito conhecido o fato de que, em países em que a rede telefônica e o acesso a computadores não era tão amplo, os celulares foram um fato importante de inclusão digital. Neste contexto, não surpreende que surja um interesse nas possibilidades de ensino por meio de mídias móveis.

Nenhuma tecnologia tem aspectos exclusivamente positivos ou negativos. É claro que os celulares têm grande abrangência e preços para todos os bolsos, tornando o acesso às tecnologias em rede mais pervasivo e barato. Com isto, os conteúdos são acessados de forma mais rápida, imediata e diversificada. No caso dos recursos para ensino, isso significa a possibilidade de novos métodos e materiais, ainda que não tenha surgido no ambiente das mídias móveis nada muito diferente das vídeo-aulas, conteúdos em texto, imagem e som ou games e apps já presentes nas formas anteriores de educação à distância. Por isto, o mobile funciona melhor como um complemento, por sua praticidade, que como uma plataforma de base para o ensino.

Por outro lado, os celulares têm telas pequenas, o que dificulta a leitura de textos mais longos ou gráficos com muitos detalhes, um inconveniente significativo no caso do ensino em mídias móveis. Não por acaso, os podcasts tem se consolidado como um formato mais acessado neste tipo de plataforma, o que faz com que o ambiente do ensino em mídias móveis implique num irônico retorno à oralidade da sala de aula. O que é ótimo até que o aparelho fique sem bateria, ou o plano de acesso da pessoa acabe bem naquela frase chave da apostila digital.

Como acontece com todas as novidades tecnológicas, sempre surgem pensadores exageradamente entusiasmados. Algo deste entusiasmo exagerado aparece em Barros (2014), quando ela considera que o planejamento de formação de pessoas, na atualidade, 
não pode ser concebido sem as tecnologias da comunicação e informação. O que a autora parece não levar em conta é que a grande maioria das Universidades faz exatamente o contrário, mantendo os formatos de ensino estabelecidos, e aproveitando os benefícios das mídias digitais apenas na medida em que eles realmente contribuam para o processo de aprendizagem.

Mas os aspectos mais críticos do ensino em mídias móveis são o ambiente entrópico dos dispositivos portáteis e a brevidade típica dos conteúdos. É difícil se concentrar num texto enquanto não param de chegar notificações de aplicativos e redes sociais. Conforme Siemens e Weller (2011 apud MATTAR, 2014), “enquanto as universidades em geral lutam para ampliar a adoção de seus ambientes virtuais de aprendizagem, enfrentam o problema oposto com as redes sociais, pois não conseguem fazer com que os alunos parem de usá-las durante as aulas".

Haikais e canções pop já provaram que formatos curtos não são superficiais, mas um dos grandes desafios do ensino em mídias móveis é obter o grau de síntese necessário para tratar de assuntos complexos em telas pequenas.

Por isso, é um equívoco supor que o ensino em mídias móveis pode substituir a aprendizagem formal. Mesmo em ambientes corporativos não é difícil antever que, para determinados tipos de treinamento — os que abordam assuntos de maior complexidade —, o método tradicional de aprendizagem se faz necessário. Santaella (2013, p. 367) ensina que

longe de substituir os processos formais de ensino, a aprendizagem ubíqua é muito mais um complemento desses processos do que um substituto deles. Quem ganha com essa complementaridade é o ser humano em formação pelo acréscimo de possibilidades que a ubiquidade lhe abre.

Conforme Garcia (2017, p. 64), um “dos caminhos seria a adoção do aprendizado presencial combinado ao online, explorando o melhor que cada um desses campos oferece, a partir do já definido conceito de blended-learning". Ele explica que: 
Blended significa 'misturado', em inglês. Assim, ocorre a 'mistura' do ensino presencial, em que se valoriza a interação entre os atores educacionais, professores e alunos, com o ensino virtual, explorando-se ferramentas da tecnologia, como celulares e mobile-learning, acessos a pesquisas, informações em tempo real.

Fica reforçada a ideia não de exclusividade, mas de complementaridade que o ensino em mídias móveis tem na relação com os métodos tradicionais de aprendizagem. Seguindo a mesma linha de raciocínio, Morán (2015, p. 2 apud GARCIA, 2017, p. 234) afirma:

que a tecnologia traz hoje é integração de todos os espaços e tempos. O ensinar e aprender acontece numa interligação simbiótica, profunda, constante entre o que chamamos mundo físico e mundo digital. Não são dois mundos ou espaços, mas um espaço estendido, uma sala de aula ampliada, que se mescla, hibridiza constantemente. Por isso a educação formal é cada vez mais blended, misturada, híbrida, porque não acontece só no espaço físico da sala de aula, mas nos múltiplos espaços do cotidiano, que incluem os digitais. O professor precisa seguir comunicando-se face a face com os alunos, mas também digitalmente, com as tecnologias móveis, equilibrando a interação com todos e com cada um.

Outra questão que não podemos perder de vista é a que diz respeito ao estilo de aprendizagem dos estudantes. Barros (2014 apud MATTAR, 2014), cita que os estilos de aprendizagem se referem a preferências e tendências altamente individualizadas de uma pessoa. Elas influenciam sua maneira de apreender um conteúdo. Ainda segundo a autora, a teoria dos estilos de aprendizagem contribui muito para a construção do processo de ensino e aprendizagem, pois leva em conta as diferenças individuais.

\section{Ubiquidade e Gamificação no Ensino}

No início deste artigo, foi afirmado que uma das particularidades do ensino em mídias móveis é a possibilidade de acesso em qualquer lugar em qualquer momento, isto é, a ubiquidade. É quase intuitivo que usemos o termo ubiquidade quando estamos tratando de ensino pelo celular, uma vez que os aparelhos mais sofisticados 
permitem acessar conteúdos em qualquer lugar na hora que desejarmos, desde que o plano contratado seja suficiente ou seja possível acessar uma rede sem fio. Por isso, um dos termos usados para descrever o ensino móvel é u-learning (do inglês Ubiquitous Learning, aprendizado ubíquo)

Segundo Liu e Hwang (2009 apud SACCOL; SCHLEMMER e BARBOSA, 2011), na aprendizagem ubíqua é possível fazer uso de ambientes de aprendizagem que utilizam diferentes tipos de 'objetos funcionais' a qualquer momento e em qualquer lugar, por meio de conexões de rede sem fio. Entenda-se como 'objetos funcionais' toda uma gama de dispositivos e sensores que propiciam uma aprendizagem que leva em conta o contexto do aprendiz. Saccol, Schlemmer e Barbosa (2011, p. 2) acrescentam:

Com isso, podemos ter aparelhos de comunicação sem fio e, ainda, identificação por radiofrequência (RFID, do inglês Radio Frequency IDentification) capazes de detectar os usuários e fornecer-lhes informações sobre o ambiente de forma personalizada. Um ambiente u-learning, portanto, integra computação, comunicação e dispositivos com sensores incorporados à vida diária, a fim de possibilitar que a aprendizagem se torne ainda mais imersiva.

Portanto, o aprendizado ubíquo sugere a possibilidade de criar ambientes que ensinam, numa forma de realidade aumentada voltada para a educação. O sonho deste formato é otimizar o tempo ocioso. Mas o desafio é descobrir o que pode ser feito que consiga oferecer diferenças capazes de ir além da boa e velha leitura de um livro ou apostila na fila do banco. Este é um equívoco no modo como se trata o conceito de portabilidade atualmente. Um olhar mais atento para a história do design mostra que o portátil sempre esteve presente, claro que sem os recursos de conectividade de aparelhos como celulares e tablets. Isto coloca o desafio de pensar o que já era possível antes de seu surgimento, e o que eles podem oferecer que realmente mude os processos de ensino e aprendizagem.

Ao tratarmos de aprendizagem ubíqua temos de considerar um outro aspecto desse tipo de aprendizagem: o contexto do apren- 
diz. O contexto é intrínseco ao aprendizado ubíquo. Para exemplificar, imaginemos um estudante de artes visitando um museu. Que tipo de informações uma camada virtual de informação poderia oferecer, para além das mais comuns neste contexto, como título, data e técnica da obra? Os aparelhos portáteis poderiam facilitar o acesso a grupos de informações menos óbvias, de leituras críticas a releituras poéticas existentes de determinadas obras, trazendo uma espécie de catálogo ampliado para o ambiente expositivo? Um contraponto que deve ser observado, relativo à questão da ubiquidade é que, por exemplo, um estudante que esteja aprendendo algo em seu celular, pode estar sujeito aos inconvenientes que o contexto pode trazer, tais como pessoas conversando, aparelhos de televisão ligados e outros ruídos, que não ocorreriam no ambiente mais focado de uma sala de aula.

Outro formato comum no ensino em mídias móveis é a chamada gamificação. Utiliza-se da estética de games, não para entretenimento, mas visando a aprendizagem. Karl Kapp (apud ALVES, 2015, p. 26) define gamificação como a "utilização de mecânica, estética e pensamento baseados em games para engajar pessoas, motivar a ação, promover a aprendizagem e resolver problemas". Na gamificação para aprendizagem, o estudante tem uma meta, recebe feedback, busca vencer e, à medida que avança nas fases do jogo, recebe pontos, medalhas ou distintivos. Isso leva a um alto grau de engajamento com o jogo e, portanto, com o aprendizado.

Jogos ajudam a aprimorar a capacidade de memória, a desenvolver o raciocínio lógico, a melhorar a concentração e o foco - algo importante numa época em que as possibilidades para dispersão são abundantes. Também ajudam no desenvolvimento de habilidades sociais, tais como aceitar tanto a vitória quanto a derrota. Segundo Abt (1987, p. 13 apud MATTAR, 2010, p. 20):

Jogos são dispositivos de ensino e treinamento efetivos para alunos de qualquer idade, e em muitas situações, porque são altamente motivadores e comunicam muito eficientemente conceitos e fatos em muitas áreas. Eles criam representações dramáticas do problema real estudado. Os jogadores 
assumem papéis realistas, encaram problemas, formulam estratégias, tomam decisões e recebem feedback rápido da consequência de suas ações.

Mas, como em toda tecnologia, nos jogos nem tudo são ganhos. Um contraponto a essas constatações positivas é apontado por Goleman (2014 apud GARCIA, 2018, p. 49):

as habilidades adquiridas pelos games não se transferem diretamente para a vida fora do vídeo, pois não ajudam no requisito mais importante para a aprendizagem, que é manter a atenção em um contexto de informações que se alteram a todo instante, como também prestar atenção à aula e compreender o que se lê e relacionar a outros fatos aprendidos anteriormente. Aí se desencadeiam conflitos entre o papel social da escola e a interação com seus aprendizes e seus novos perfis.

É comum que aprendizes que participam dos mesmos treinamentos queiram revelar os pontos já adquiridos no jogo para seus colegas, visando comparar com os pontos adquiridos por aqueles. Tanto que em muitos games é comum o acesso a um leaderboard, que nada mais é que um ranking onde os jogadores podem ver a sua colocação e a dos demais colegas que jogam o mesmo game.

Quando o aprendiz joga, ele está num espaço delimitado, que o separa da realidade. Huizinga, autor de Homo Ludens, chamou esse espaço de Círculo Mágico. Segundo a teoria do Círculo Mágico, ao cruzar a fronteira que separa a realidade do espaço do jogo, o jogador muda o seu 'eu', indo do 'eu comum' para um 'eu lúdico’. O historiador destaca uma característica positiva do jogar, que é o fato de criar e exigir ordem absoluta e suprema, criando uma perfeição limitada e temporária num mundo imperfeito.

Esta busca por um mundo sem ruídos assusta, na medida em que pode resvalar para a intolerância, a incapacidade de aceitar o provisório e as diferenças. O problema dos jogos está justamente nesta dimensão ideológica problemática, que estimula o vencer, o evitar os erros. Enfim, uma série de pensamentos que podem tanto estimular a competição saudável quanto disputas bélicas. É preciso levar em conta estes riscos, para não transformar os processos de 
gamificação num trampolim para um capitalismo exacerbado em seus piores aspectos. O lúdico é mais importante que a dimensão competitiva, neste contexto.

Aprender com eficiência exige concentração, algo que os games nos obrigam a ter para superarmos os obstáculos que vão se enfileirando na jornada do jogo. Conforme Alves (2015, p. 40), "para nós, em termos de aprendizagem, um dos maiores benefícios é o fato de que os games diminuem sensivelmente o tempo necessário para o aprendizado de um conceito, pois focados na essência do game diminuímos as resistências provenientes da realidade."

Uma outra vantagem dos games é a maneira como se lida com o erro. De acordo com Mattar (2014, p. 48), "nos games, o custo do fracasso é normalmente diminuído — quando os jogadores fracassam, eles podem por exemplo recomeçar de seu último jogo salvo." Isso nos remete ao método de aprendizagem construtivista, em que o erro é visto como parte útil no processo de aprendizagem, não devendo ser evitado ou repudiado. Mas gamificar não é apenas criar distintivos, um leaderboard e um jogo divertido. Deve-se ter em mente como envolver e motivar os jogadores / estudantes. Ao abusar na concessão de medalhas e coisas do tipo, corre-se o risco de cair no 'lugar-comum'. Fardo (2013, p. 4) alerta para o fato de que a gamificação não deve se restringir à ideia de motivar os alunos com prêmios para suas notas:

Pode ainda ser empregada de forma incorreta ou equivocada, reforçando mais ainda alguns problemas presentes no sistema de ensino atual como, por exemplo, o fato de ocorrer uma valorização maior das notas obtidas do que da aprendizagem em si (LEE e HAMMER, 2011). Isso pode acontecer se, ao aplicarmos a gamificação, utilizarmos apenas as mecânicas mais básicas dos games e com isso construirmos somente um sistema mais complexo de pontuação, por exemplo.

Burke (2015) cita uma iniciativa de 2011 do Google, que tinha o objetivo de incentivar a leitura das Notícias Google. Para isso, foram criados mais de 500 distintivos para abarcar diferentes 
assuntos em níveis diversos, visando premiar o engajamento com a leitura. Não deu certo. Não ficou claro para os leitores por que eles deveriam valorizar os distintivos. Pareceu não haver alinhamento entre a iniciativa e a motivação das pessoas. Ainda conforme Burke (ibid.), soluções gamificadas bem-sucedidas envolvem os jogadores em um nível emocional. Portanto, não é uma boa ideia gamificar apenas porque é uma tendência, ou apenas para fazer algo diferente. Importante que antes de gamificar a instituição defina quais os resultados que ela quer alcançar com a gamificação.

Além disso, trabalhar com o emocional das pessoas implica uma responsabilidade enorme. $\mathrm{O}$ capitalismo contemporâneo vem inventando formas perversas de explorar o conhecimento obtido sobre as pessoas, por meio do mapeamento de padrões em redes sociais e aplicativos. Isto leva a uma economia que sequestra a atenção em tempo integral, conforme discutido por Crary, em 24/7 - Capitalismo tardio e os fins do sono ${ }^{2}$. Por isto, ao usar os processos de gamificação no ensino, é preciso procurar uma atitude responsável, que explora antes a dimensão lúdica do aprendizado que os aspectos mais competitivos dos jogos, visando estabelecer sujeitos envolvidos em afetos diversos e inclusivos. Mattar sinaliza nesta direção, quando lembra Huizinga (1938 apud MATTAR, 2010, p. 16):

Em época mais otimista que a atual, nossa espécie recebeu a designação de Homo sapiens. Com o passar do tempo, acabamos por compreender que afinal de contas não somos tão racionais quanto a ingenuidade e o culto da razão do século XVIII nos fizeram supor, e passou a ser moda designar nossa espécie como Homo faber. Embora faber não seja uma definição do ser humano tão inadequada como sapiens, ela é, contudo, ainda menos apropriada do que esta, visto poder servir para designar grande número de animais. Mas existe uma terceira função, que se verifica tanto na vida humana como na animal, e é tão importante como o raciocínio e o fabrico de objetos: o jogo. Creio que, depois de Homo faber e talvez ao mesmo nível de Homo sapiens, a expressão Homo ludens merece um lugar em nossa nomenclatura.

2 Crary, Jonathan. 24/7. Capitalismo tardio e os fins do sono. São Paulo: Ubu, 2013. 
Mas como estas questões tem sido exploradas, nas práticas de ensino? A Universidade de Aveiro, em Portugal, oferece um exemplo que permite examinar mais de perto a implementação das possibilidades de ensino móvel. O aplicativo EduPark envolveu 86 alunos de graduação do segundo ano do curso de Educação Básica do Departamento de Educação e Psicologia. Inicialmente, o aplicativo foi apresentado aos alunos, de maneira que eles tomassem conhecimento de suas características. Além de gamificação, ele também fez uso de realidade aumentada. A experiência prévia dos estudantes com gamificaşão e realidade aumentada era bastante escassa. As atividades de aprendizagem foram realizadas no Parque Infante D. Pedro e tiveram durações que giraram em torno de uma hora e quarenta minutos. Os estudantes foram separados em grupos com 3 integrantes. Eles fizeram uso do aplicativo no parque e emitiram suas opiniões sobre os processos de ensino móvel, a usabilidade do EduPark e o impacto dessa estratégia educacional em termos de motivação intrínseca e aprendizagem real.

Os dados foram coletados através de uma pesquisa e de uma coleção de documentos com as reflexões dos estudantes. Foi solicitado aos estudantes participantes que preenchessem um questionário individual cerca de uma semana depois da experiência. A taxa de resposta foi $100 \%$. O questionário incluiu principalmente questões fechadas de múltipla escolha, seleção de itens e escala Likert de cinco pontos, apesar de também conter questões abertas. Quanto aos documentos com as reflexões dos estudantes, o objetivo foi apoiar a compreensão de alguns resultados da pesquisa. Foi solicitado a eles que incluíssem suas reflexões sobre o possível impacto do uso do EduPARK no valor da aprendizagem, na motivação intrínseca, no comprometimento, na aprendizagem autêntica, no aprendizado duradouro e nos hábitos de conservação e sustentabilidade.

No início do game, os jogadores são recebidos por uma mascote do projeto, uma macaquinha, que conversa com uma amigável voz humana. A mascote explica a estrutura do jogo e aponta o objetivo principal, de ganhar pontos respondendo corretamente 
as perguntas, entre outras características relevantes. A maioria dos quizzes com os quais o jogador se depara são estilo múltipla escolha, como na imagem 1. Algumas questões podem ter mais de uma resposta correta, o que estimula a concentração do jogador e faz com que ele negocie com os integrantes do grupo antes de responder. O jogador recebe feedback imediato de suas respostas, se está certa ou errada, explicando a resposta correta ou fornecendo informação adicional sobre o tema, como na imagem 2 .

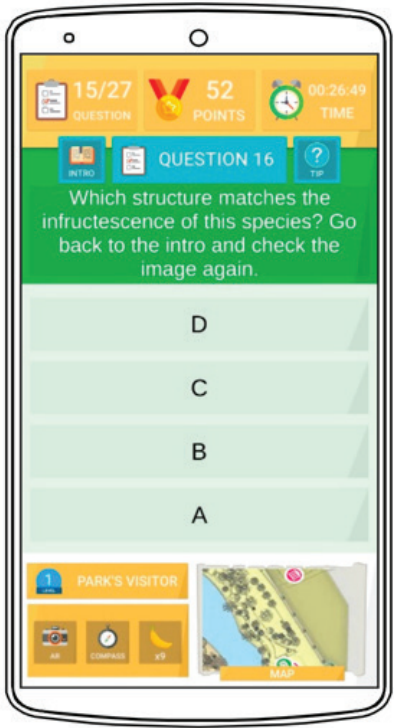

IMAGEM 1

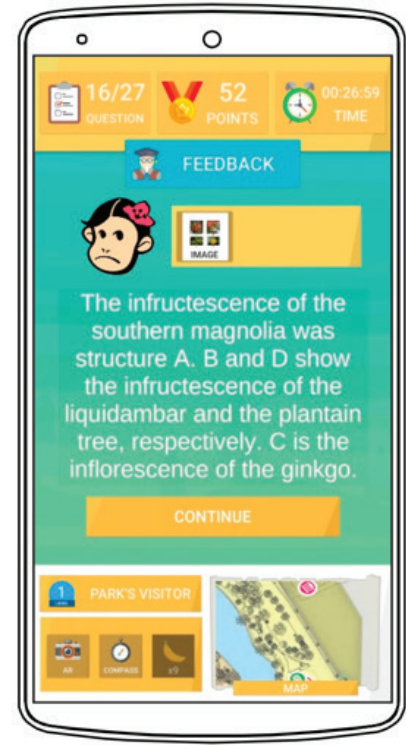

IMAGEM 2

O jogo está organizado em quatro estágios, cada um correspondente a um caminho com qui geralmente de múltipla escolha, que deve ser respondido enquanto os jogadores estão numa zona específica do parque, conforme o mapa do aplicativo, como na imagem 3. O aplicativo leva os jogadores a procurarem por marcadores de realidade aumentada no parque que fornecerão informação para as respostas de certos quizzes, como na imagem 4. 


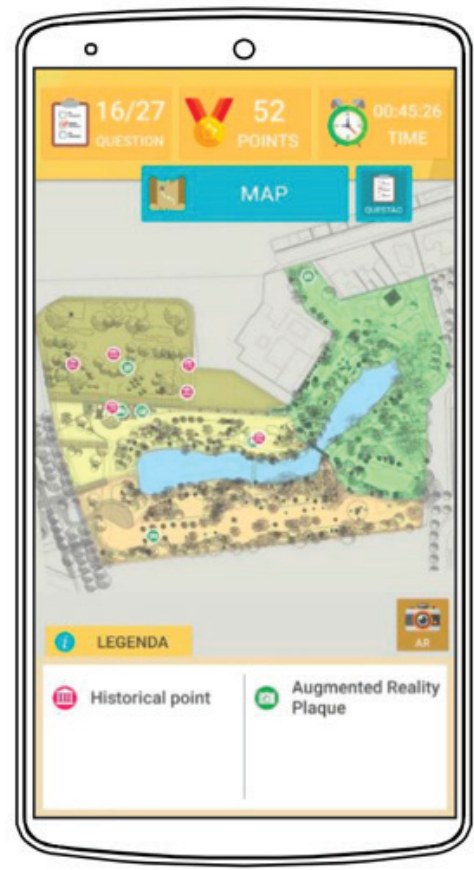

IMAGEM 3

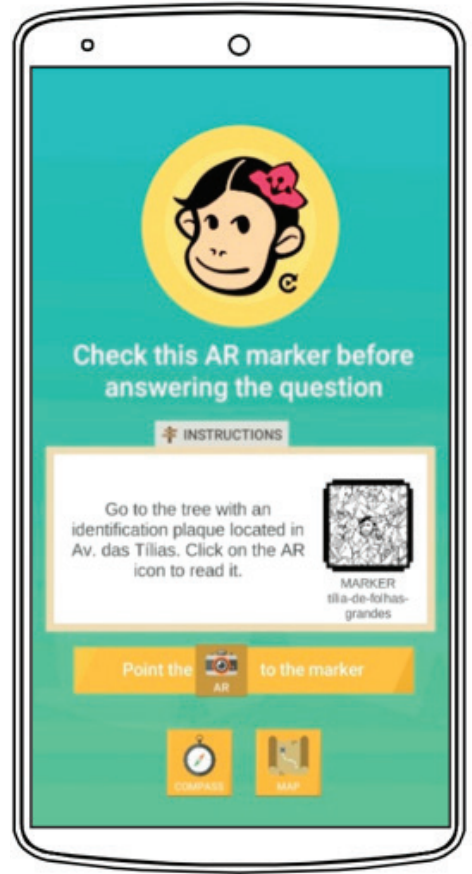

IMAGEM 4

Os marcadores estão impressos nas placas próximas às amostras botânicas de diferentes espécies, selecionadas como representantes da riqueza biológica do parque, como na imagem 5. Todas as placas possuem o mesmo layout. A informação contida em cada placa varia conforme o espécime botânico: os nomes vulgar e científico, sua família (na classificação biológica), sua origem e o marcador de realidade aumentada com a mascote do projeto. O conteúdo de realidade aumentada associada a cada placa inclui recursos sobre as espécies identificadas (textos, fotos, vídeos, modelos 3D), como na imagem 6. 

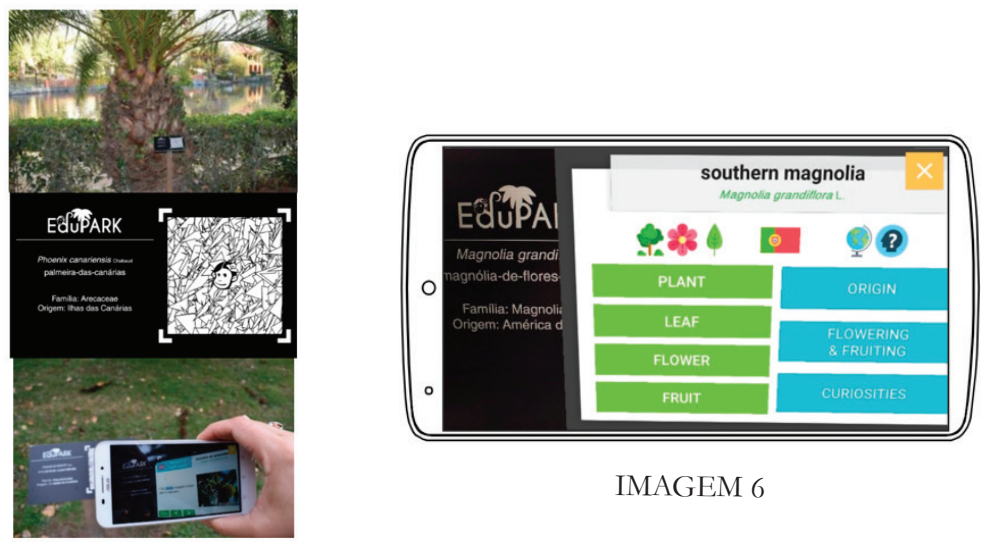

IMAGEM 6

\section{IMAGEM 5}

Uma mecânica de jogos que foi incorporada para aumentar a motivação dos jogadores é receber uma pista / charada para encontrar uma provisão virtual no final de cada fase do game, como nas imagens 7 e 8 .

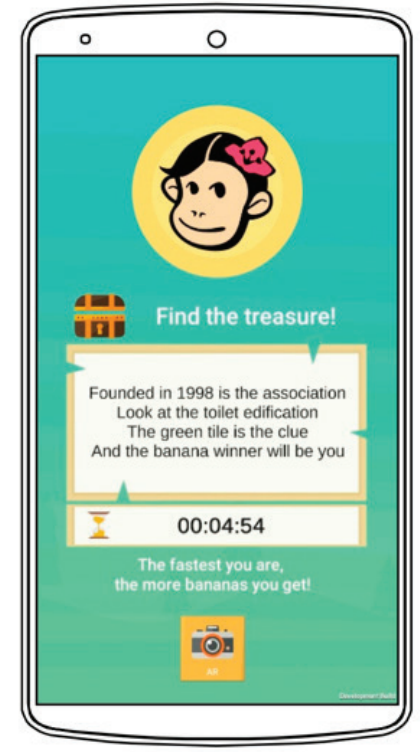

IMAGEM 7

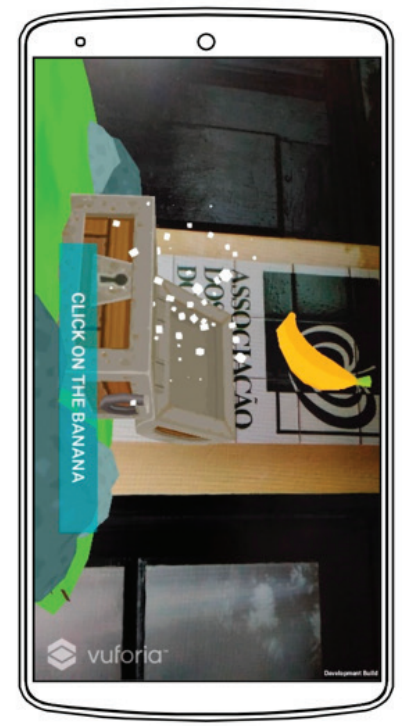

IMAGEM 8 
Se a provisão é encontrada dentro de um período de $5 \mathrm{mi}$ nutos, os jogadores ganham pontos e bananas virtuais que podem ser trocadas para ajudá-los com as questões seguintes. No fim do jogo, o aplicativo exibe dados como pontuação, respostas corretas e o tempo no jogo, como na imagem 9.

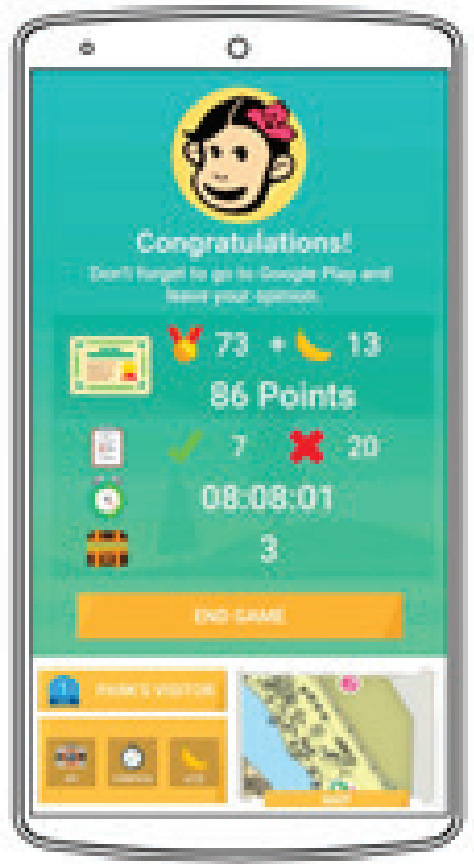

IMAGEM 9

$\mathrm{Na}$ pesquisa, ficou claro que, quanto às vantagens de se usar dispositivos móveis para aprendizagem, 100\% dos estudantes mencionaram ao menos uma. As vantagens identificadas foram categorizadas em 'metodologias de aprendizagem' — com as subcategorias 'ganhos para os aprendizes' e 'ganhos para a prática de aprendizagem' - e 'suporte da tecnologia para aprendizagem' - com as subcategorias 'características dos dispositivos móveis' e 'características dos usuários'. 
Os estudantes consideraram vários 'ganhos para os aprendizes', tais como a efetividade das mídias móveis quando usadas para aprendizagem. Eles consideraram que os dispositivos de fato suportaram a aprendizagem (20 menções). Os estudantes também mencionaram que as mídias móveis aumentam a motivação (10 menções) e provavelmente o engajamento (somente uma menção). A vantagem relacionada à 'prática de aprendizagem' mencionada pelos estudantes foi a 'diversificação das estratégias de aprendizagem’ (cinco menções).

Relacionado ao 'suporte da tecnologia para aprendizagem', os estudantes valorizaram tal suporte, especialmente o fato de que o dispositivo móvel 'aprimora o acesso à informação (30 menções). Outras características reconhecidas foram as seguintes: 'alta portabilidade' (oito menções), permitindo atividades ao ar livre; 'disponibilidade de recursos' (três menções); 'suporte à interatividade' (uma menção); ser 'eco-friendly' (uma menção). Quanto às 'características dos usuários', a 'familiaridade com a tecnologia dos dispositivos móveis' dos estudantes (cinco menções) e 'uso responsável' (uma menção) também foram apontados. Vale a pena notar que os estudantes consideraram que o uso das tecnologias móveis para aprendizagem em cenários ao ar livre pode levar a uma mudança de mentalidade na comunidade.

Quando questionados sobre as restrições no uso dos dispositivos móveis para aprendizagem, 18 estudantes não identificaram nenhuma restrição e 68 estudantes mencionaram ao menos uma restrição. Similarmente às vantagens, as restrições do ensino em mídias móveis apontadas pelos estudantes foram distribuídas em duas categorias: 'metodologias de aprendizagem' - com as subcategorias 'no nível da instituição' e 'no nível do estudante' - e 'suporte da tecnologia para aprendizagem', com as subcategorias 'relacionado à tecnologia' e 'características dos usuários'. 'No nível da instituição', um estudante mencionou a 'proibição da tecnologia' de dispositivo móvel. 'No nível do estudante', as 'distrações' potencialmente suportadas pelos dispositivos móveis tiveram algu- 
ma relevância (13 menções). 'Sobrecarga cognitiva', devido à alta quantidade e, frequentemente, má qualidade da informação acessada através dos dispositivos móveis, também foram mencionados (9 menções). A 'falta de habilidades tecnológicas' dos estudantes que não estão no nível superior foi mencionada uma vez. A depreciação de outros métodos de aprendizagem, especificamente aqueles através dos livros impressos, foi uma preocupação de dois estudantes.

No que se refere às restrições 'relacionadas à tecnologia', a mais frequentemente citada foi 'informação de internet errada', revelando uma preocupação dos estudantes com a confiabilidade da informação que eles acessam através dos dispositivos móveis. Outras questões: 'conectividade limitada' por nenhum acesso à web ou conexão lenta à web (quatro menções); 'limitações computacionais', que resulta em lentidão na execução da tarefa e que até pode tornar a interação com o dispositivo móvel mais difícil (três menções); “limitações de visualização', devido à tela pequena dos dispositivos, comparada à tela de um computador (uma menção).

Finalmente, em 'características dos usuários' identificou-se que algumas questões podem atrapalhar o ensino em mídias móveis, especialmente o desenvolvimento de 'questões relacionadas à saúde', tais como o risco de desenvolver dependência aos dispositivos móveis e deficiência na visão (sete menções). Outras características dos usuários foram a possibilidade de 'não familiaridade com a tecnologia móvel' e 'percepções de tecnologia' móvel que associam esses dispositivos somente com atividades recreativas (uma menção cada uma).

Outra questão sobre a qual os estudantes expressaram suas opiniões foi referente à usabilidade do EduPARK. Por exemplo, a mais relevante questão de usabilidade foi afirmar que 'o app absorve recursos de memória, que algumas vezes causa uma falha no dispositivo'. Isso indica que o número e o tamanho do arquivo dos recursos de multimídia do $a p p$, como imagens e vídeos, deveria ser reduzido. Mas a maioria dos comentários dos estudantes apontou que não havia nada a melhorar referente à usabilidade do app. 
Referente à avaliação dos estudantes quanto à atividade EduPARK em si, eles foram inicialmente desafiados a ranquear seu grau de relevância, numa escala de 1 a 5 (onde 1 é não relevante e 5 é muito relevante), com respeito a: valor de aprendizagem; motivação intrínseca; engajamento; aprendizagem autêntica; aprendizado duradouro; hábitos de conservação e sustentabilidade. Abaixo, as respostas dos estudantes:

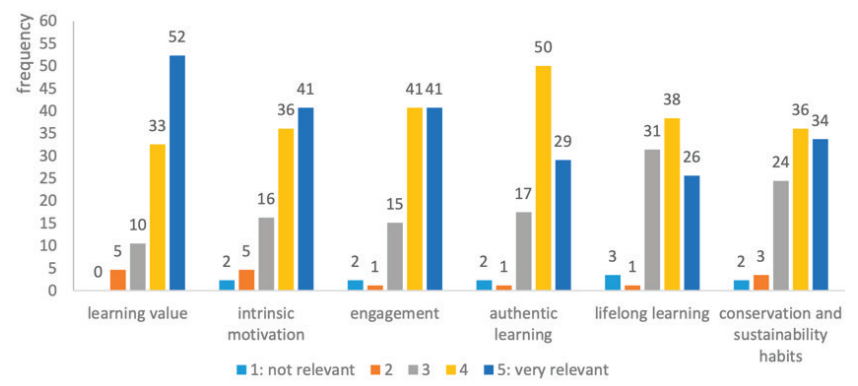

Nota-se que para quase todos os 6 quesitos as notas 4 e 5 foram prevalentes, o que nos parece bastante auspicioso no tocante à real percepção dos estudantes quanto a uma atividade que lançou mão do ensino em mídias móveis.

Convém destacar que o EduPARK foi o vencedor do 2018 ECIU (European Consortium of Innovative Universities) Team Award for Innovation in Teaching and Learning. Um dos destaques apontados pelo júri foi o uso educativo de realidade aumentada nas tecnologias cotidianas, tais como os smartphones e o fato de a iniciativa do EduPARK ter desafiado o pensamento convencional sobre as maneiras como as pessoas aprendem.

Talvez estejamos vivendo o início do tempo de uma das maiores transformações pelas quais o ensino e a aprendizagem já passaram. O Mobile Learning surgiu a reboque de uma transformação ainda maior, a da transformação da sociedade numa sociedade nomádica. Nesse artigo tratamos da aprendizagem que ocorre especialmente através dos smartphones, o ensino para mídias móveis. Entre aspectos positivos e negativos, os desafios se colocam em meio às possibilidades educacionais em novas mídias que vêm 
amadurecendo ao longo dos anos, mas ainda não chegaram a gerar resultados significativamente diferenciados, na medida em que servem antes como complementos à educação em sala de aula, que como substitutos. Para atingir este patamar, é preciso que o ensino à distância e o ensino para mídias móveis procurem recursos que os levem além de emular em ambientes digitais as possibilidades dos ambientes físicos de ensino.

\section{Referências}

ALVES, Flora. Gamification: como criar experiências de aprendizagem engajadoras. Um guia completo: do conceito à prática. 2. ed. São Paulo: DVS Editora, 2015.

BARROS, Daniela Melaré Vieira. Estilos de aprendizagem e o uso das tecnologias. 1. ed. São Paulo: Artesanato Educacional, 2014.

BURKE, Brian. Gamificar: como a gamificação motiva as pessoas a fazerem coisas extraordinárias.São Paulo: DVS Editora, 2015.

ESTATÍSTICAS do Brasil - geral. Teleco, 2019. Disponível em: <https://www. teleco.com.br/estatis.asp>. Acesso em: 29 set. 2019.

FARDO, Marcelo Luis. A gamificação como estratégia pedagógica: estudo de elementos dos games aplicados em processos de ensino e aprendizagem. 2013. 104 f. Dissertação (Mestrado em Educação) - Universidade de Caxias do Sul, Caxias do Sul.

GARCIA, Marilene Santana dos Santos. Mobilidade tecnológica e planejamento didático. São Paulo: Ed. Senac, 2018.

GOLEMAN, Daniel. Focus: the hidden driver of excellence. UK: Bloomsbury, 2013.

HYMAS, Charles. A decade of smartphones: we now spend an entire day every week online. The Telegraph, 02 ago. 2018. Disponível em: <https://www.telegraph.co.uk/news/2018/08/01/decade- smartphones-now-spend-entire-day-every-week-online/>. Acesso em: 29 set. 2019.

LU, Tina. Almost half of smartphone users spend more than 5 hours a day on their mobile device. Counterpoint, 2017. Disponível em: <https://www.counterpointresearch.com/almost-half-of-smartphone-users-spend-more-than-5-hours-a-day-on-their-mobile-device/> . Acesso em: 22 set. 2019. 
MATTAR, João. Games em educação: como os nativos digitais aprendem. São Paulo: Pearson Prentice Hall, 2010.

Design educacional: educação a distância na prática. 1. ed. São Paulo: Artesanato Educacional, 2014.

SANTAELLA, Lucia. Desafios da ubiquidade para a educação. 2013. Disponível em: <https://www.revistaensinosuperior.gr.unicamp.br/artigos/desafios-da-ubiquidade-para-a-educacao >. Acesso em: 26 ago. 2019.

SACCOL, Amarolinda; SCHLEMMER, Eliane; BARBOSA, Jorge. M-learning e u-learning: novas perspectivas da aprendizagem móvel e ubíqua. São Paulo: Pearson Prentice Hall, 2011.SOPRANA, Paula. Acesso à internet sem fio cresce nas escolas públicas, mas velocidade é desafio.Época, 03 ago. 2017. Experiências digitais. Disponível em:<https://epoca.globo.com/tecnologia/experiencias-digitais/noticia/2017/08/acesso-internet-sem-fio-cresce-nas-escolas-publicas-mas-velocidade-ainda-e-desafio.html>. Acesso em: 13 jun. 2020.

JOGAR games uma hora por dia ajuda a 'treinar' o cérebro. Veja, 14 mar. 2013. Saúde. Disponível em: <https://veja.abril.com.br/saude/jogar-games-uma-hora-por-dia-ajuda-a-treinar-o-cerebro/>. Acesso em: 11 jun. 2020.

POMBO, Lúcia; MARQUES, Margarida M. An app that changes mentalities about mobile learning - The EduPARK augmented reality activity. Computers, v. 8(2), jun. 2019.

SIEMENS, George. Conectivismo: uma teoria da aprendizagem para a era digital. Humana aprendizagem interativa, 2007. Disponível em: <http://humana.social/conectivismo-una-teoria-da-aprendizagem-para-a-era-digital/ $>$. Acesso em: 07 out. 2019.

SENGE, Peter M.. A quinta disciplina: arte e prática da organização que aprende. Tradução: Gabriel Zide Neto. 29. ed. Rio de Janeiro: Best Seller, 2013. 